\title{
Observatório
}

\section{APRENDIZAGEM COM MOBILIDADE EM PRÁTICAS \\ DE ROLE PLAYING GAME EM CONTEXTO NÃO- FORMAL DE ENSINO}

MOBILE LEARNING IN ROLE PLAYING GAME PRACTICES AT A CONTEXT OF NON-FORMAL EDUCATION

APRENDIZAJE MÓVIL EN PRÁCTICAS

DE ROLE PLAYING GAME EN CONTEXTO NO-FORMAL DE ENSINO

\section{Débora Nice Ferrari Barbosa ${ }^{1}$ \\ Maria Rosangela Bez ${ }^{2}$ \\ Paulo Ricardo Dos Santos ${ }^{3,4}$}

\section{RESUMO}

O presente artigo visa demonstrar como práticas pedagógicas com uso de tecnologias móveis podem contribuir para os processos de letramento, alfabetização e nos déficits de aprendizagem de crianças e adolescentes em tratamento oncológico em um contexto não-formal de ensino. A pesquisa, desenvolvida em uma instituição de apoio à criança com câncer, contemplou oficinas envolvendo jogos temáticos de Role Playing Game e atividades de

\footnotetext{
${ }^{1}$ Doutora e Mestre em Ciência da Computação pela Universidade Federal do Rio Grande do Sul (UFRGS) e Bacharel em Análise de Sistemas pela Universidade Católica de Pelotas (UCPel). Professora e pesquisadora do Programa de Pós-graduação em Diversidade Cultural e Inclusão Social, do Mestrado Profissional em Letras e dos cursos de Sistemas de Informação e Ciência da Computação da Universidade Feevale. Bolsista de Produtividade em Desenvolvimento Tecnológico e Extensão Inovadora - DT-nivel 2 do CNPq.E-mail: deboranice@feevale.br

${ }^{2}$ Doutora em Informática na Educação - PPGIE/UFRGS, Mestre em Educação - PPGEDU/UFRGS, Licenciatura em Computação - FEEVALE. Pós-Doutorado em Andamento - FEEVALE. Email: mariabez@feevale.br.

${ }^{3}$ Graduando do Curso de Letras - Português e Inglês e bolsista de Iniciação Científica da Universidade Feevale. E-mail: paulords1994@gmail.com.

4 Endereço de contato com a autora: Universidade FEEVALE. ERS 239, 2755 - Vila Nova, Novo Hamburgo - RS, 93525-075, Brasil.
} 


\section{Observatório}

leitura, escrita e raciocínio lógico utilizando aplicativos e recursos de dispositivos móveis tablets. Os resultados apontaram contribuições no desenvolvimento dos déficits de aprendizagem e linguístico, bem como no ensino voltado ao letramento como prática social.

PALAVRAS-CHAVE: aprendizagem com mobilidade; role playing game; desenvolvimento linguístico; letramento.

\section{ABSTRACT}

This article shows how pedagogical practices using mobile technologies can contribute to the literacy processes of children and adolescents in oncological treatment. The research, developed at a cancer support institution, used practices envolving Role Playing Games and reading, writing, and logical reasoning activities. The practicies were based by using apps and other mobile devices resources, as tablets, and the results shows that the students increased their learning according research goals.

KEYWORDS: mobile learning; role playing game; linguistic development; literacy.

\section{RESUMEN}

El presente artículo pretende demostrar cómo prácticas pedagógicas con uso de tecnologías móviles pueden contribuir a los procesos de letra, alfabetización y en los déficit de aprendizaje de niños y adolescentes en tratamiento oncológico en un contexto no formal de enseñanza. La investigación, desarrollada en una institución de apoyo al niño con cáncer, contempló talleres que involucra juegos temáticos de Role Playing Game y actividades de lectura, escritura y raciocinio lógico utilizando aplicaciones y recursos de dispositivos móviles tablets. Los resultados apuntaron a las contribuciones en el desarrollo de los déficit de aprendizaje y lingüístico, así como en la enseñanza orientada al literal como práctica social. 


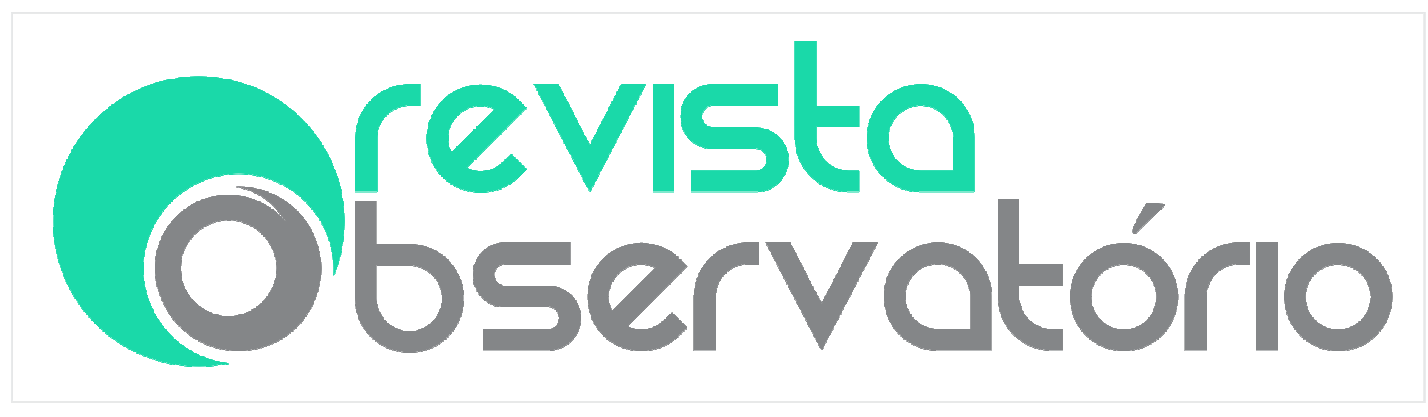

ISSN n² 2447-4266

Vol. 4, n. 3, maio. 2018

DOI: https://doi.org/10.20873/uft.2447-4266.2018v4n3p540

PALABRAS CLAVE: aprendizaje móvil; role playing game, desarrollo linguístico; letramiento.

Recebido em: 30.11.2017. Aceito em: 20.02.2018. Publicado em: 29.04.2018. 


\section{Observatório}

ISSN n² 2447-4266

Vol. 4, n. 3, maio. 2018

DOI: https://doi.org/10.20873/uft.2447-4266.2018v4n3p540

\section{Introdução}

A tecnologia faz parte da educação. Não apenas da educação formal, mas, de maneira ampla, do processo diário de aprendizagem educacional e profissional dos sujeitos que compõem a sociedade. Tecnologias digitais, como smartphones, tablets, computadores desktop e notebooks, fazem parte da rotina de milhões de pessoas, que, por meio dessas ferramentas, têm acesso à informação sem limites, comunicação sem fronteiras e podem produzir conhecimento e compartilhá-lo instantaneamente em espaços virtuais disponíveis na web. Nesses espaços, circulam artigos, e-books, vídeo-aulas, imagens e outros recursos para acesso à informação; há também ferramentas como word, excel, power point, google docs, entre outras, para produção de conhecimento; e há plataformas para compartilhamento, como redes sociais, blogs, periódicos eletrônicos, entre outros, onde é possível divulgar, debater, comentar e avaliar o conteúdo produzido pelos usuários. Todos esses instrumentos ampliam as possibilidades de produção e acesso ao conhecimento, sendo algumas delas de uso comum aos nativos digitais, pessoas que já nasceram em meio a esse contexto tecnológico (PRENSKY, 2012).

Para um uso eficiente das tecnologias da informação, torna-se cada vez mais necessário que os usuários, além de serem letrados no uso da linguagem verbal, saibam também interagir com a multiplicidade de letramentos e signos que compõem os espaços virtuais. O sujeito dos dias de hoje precisa de novos saberes para lidar com as novas formas de acesso à informação e interação (KERSH \& RABELLO, 2016). Nas mídias, nas redes sociais, nos sites, enfim, nos espaços da web, a quantidade de usuários dos mais variados países, culturas e contextos cria um local intensamente marcado pela diversidade social, 


\section{Observatório}

ISSN n² 2447-4266

Vol. 4, n. 3, maio. 2018

DOI: https://doi.org/10.20873/uft.2447-4266.2018v4n3p540

manifestada através da variedade de gêneros textuais e signos que se interrelacionam no meio virtual atendendo às necessidades comunicacionais dos indivíduos.

Nesse contexto, práticas pedagógicas que envolvem mobilidade e jogos digitais em contexto não-formal de educação, são realizadas numa instituição oncológica infantil por professores e bolsistas das áreas de Letras, Sistemas de Informação e Jogos Digitais de uma universidade do Rio grande do Sul. As práticas pedagógicas fazem uso de tecnologias móveis para apoiar o desenvolvimento dos processos de ensino e aprendizagem e na defasagem curricular das crianças que participam das oficinas, além de promover um ensino voltado ao letramento como prática social.

Sendo assim, o foco deste artigo é relatar as práticas com dispositivos móveis tablets e jogos de Role Playing Game (RPG) desenvolvidas no contexto da educação não-formal de ensino, que ocorreram no segundo semestre de 2016 em uma instituição de tratamento e apoio para crianças com câncer. As oficinas de aprendizagem com mobilidade contemplam crianças e adolescentes em tratamento oncológico e seus familiares e tem por objetivo principal auxiliar no desenvolvimento da leitura, escrita e raciocínio lógico, trabalhando com uso de tablets, promovendo um trabalho focado no reforço escolar, no aumento da autoestima dos pacientes e na sua inclusão e acesso às novas tecnologias de comunicação.

O artigo está dividido da seguinte forma: após a introdução, apresentase o embasamento teórico acerca dos conceitos de letramentos e de aprendizagem com tecnologias móveis. Na sequência, discorre-se sobre educação não-formal e sobre jogos de Role Playing Game. Logo após, na seção 4, encontra-se o referencial metodológico e na seção 5 o relato das práticas. Em 


\section{Observatório}

ISSN n² 2447-4266

Vol. 4, n. 3, maio. 2018

DOI: https://doi.org/10.20873/uft.2447-4266.2018v4n3p540

seguida, são discutidos os resultados obtidos na pesquisa, para, então, apresentação das considerações finais.

\section{Aprendizagem com mobilidade e as novas metodologias de ensino}

Atualmente, com a consolidação das tecnologias de informação e comunicação ( $\mathrm{TIC}^{\prime}$ s) no cotidiano da sociedade, a escrita e leitura vêm crescendo cada vez mais como instrumentos de interação social, através do acesso à informação via web e da comunicação via aplicativos de mensagem instantânea, tais como Whatsapp e Messenger. O uso da linguagem escrita, nesse caso a escrita digital, acontece como parte das relações diárias entre os sujeitos que utilizam as tecnologias. Dentre esses, crianças e adolescentes representam uma parcela significativa, pois já nasceram em um ambiente onde tais ferramentas estão naturalmente contextualizadas, diferente das outras gerações que só foram ter acesso às TIC's quando adultos (PRENSKY, 2001). Nessa perspectiva, se o ensino escolar atende às demandas da geração vigente de estudantes, é natural que atualizações tecnológicas e metodológicas sejam feitas nos processos educativos, pois muitos jovens já têm contato com as tecnologias antes mesmo de aprenderem a ler e a escrever.

A atualização nas metodologias é orientada para que as estratégias de ensino de leitura e escrita desenvolvidas com uso de tecnologias correspondam a práticas efetivas e inovadoras, de modo que o uso de ferramentas digitais favoreça e contribua nesse processo de ensino. Não basta trocar ferramentas antiquadas por instrumentos novos, são necessárias mudanças no referencial metodológico e nas sequências didáticas para que as tecnologias possibilitem atividades inovadoras, colaborativas e interativas, aproveitando o potencial de tais ferramentas (PRENSKY, 2012). 


\section{Observatório}

ISSN n² 2447-4266

Vol. 4, n. 3, maio. 2018

DOI: https://doi.org/10.20873/uft.2447-4266.2018v4n3p540

Portanto, para a realização de práticas pedagógicas com uso de tecnologia é importante conhecer bem as ferramentas para compreender o que esses dispositivos possibilitam ao aluno produzir, para que o uso das TIC's não se torne uma substituição de ferramentas. Segundo Matias, "é importante ressaltar que computadores são instrumentos. Por isso, assemelham-se a procedimentos metodológicos" (MATIAS, 2016, p. 169). Assim, volta-se a atenção para a elaboração de novas estratégias de leitura e escrita, contextualizando-as em atividades nas quais o aluno seja um produtor ativo de conteúdo, já que possui o espaço na web para debater, pesquisar e divulgar o conhecimento, o que faz com que a escrita possa "se tornar mais significativa, por pressupor outros leitores, além do professor, e uma prática social autêntica" (MATIAS, 2016, p. 172).

A partir da noção de que as tecnologias são um recurso metodológico, volta-se atenção também aos conceitos que orientam as temáticas e conteúdos do ensino escolar. Com relação ao ensino de língua materna, as discussões atuais têm observado que o enfoque das aulas de língua portuguesa não está mais na apreensão de gramática e em assuntos desconectados da realidade. Efetivam-se teorias linguísticas foquem para a necessidade de fazer da leitura e escrita uma prática social, através de competências que ajudam o aluno a compreender de que maneira se concretiza o uso da língua em um contexto social.

\section{a)Desenvolvimento linguístico e letramento: conceitos básicos}

Para se considerar um ensino efetivo em ambientes de ensino nãoformal, é importante também rever conceitos chaves que orientam o ensino de línguas no país. Se antes o ensino da variedade escrita da língua consistia em 


\section{Observatório}

ISSN n² 2447-4266

Vol. 4, n. 3, maio. 2018

DOI: https://doi.org/10.20873/uft.2447-4266.2018v4n3p540

apenas aprender a decifrar e a reproduzir o código linguístico, hoje entende-se que a escrita é também instrumento de interação (KOCH \& ELIAS, 2009) que serve a diferentes propósitos, de acordo com os tipos de textos que circulam socialmente. Nessa perspectiva, Kersch \& Rabello " (2016, p. 53), citam que "leitura (e por extensão, a escrita) é entendida como interação, como diálogo entre sujeitos historicamente construídos. Porém, para que o jovem saiba interagir por meio da leitura e escrita, não basta que ele seja alfabetizado, ou seja, que saiba ler e escrever, mas também que ele seja letrado, ou seja, que conheça as variedades oral e escrita da língua de modo que obtenha conhecimentos necessários para atender ao uso social da linguagem (SOARES, 1998).

Entende-se, então, que ensinar o jovem a utilizar a língua socialmente demanda um trabalho mais apurado do que simplesmente mostra-lhe os traços básicos das letras, o significado das palavras e sua ortografia oficial. Tornar-se capaz de se expressar discursivamente e socialmente através da linguagem textual demanda um conjunto de fatores e aspectos a serem trabalhados de forma contínua ao longo do ensino. Segundo Travaglia (2015), um dos objetivos das práticas de letramento é fazer com que o aluno adquira um conhecimento linguístico para que alcance, progressivamente

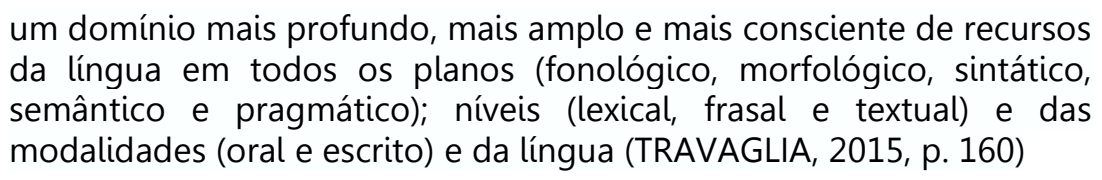

Nessas práticas, a oralidade também deve ser considerada, pois, através das interações, os alunos aprendem a utilizar os recursos da língua da maneira mais apropriada. Segundo Wolff e Nazari (2009, p. 156), a língua oral constitui uma base fonológica, sintática e semântica para o estudante, permitindo que, 


\section{Observatório}

ISSN n² 2447-4266

Vol. 4, n. 3, maio. 2018

DOI: https://doi.org/10.20873/uft.2447-4266.2018v4n3p540

através de um uso ativo da linguagem, empregue as palavras desenvolvendo sua capacidade de "conhecer diferenças e semelhanças em categorias verbais, manejar relações gramaticais, codificar foneticamente a informação gráfica, entre outras habilidades".

Todo esse conhecimento possibilitará que o estudante saiba compreender os inúmeros gêneros textuais de acordo com os recursos linguísticos que os compõem. Isso é saber utilizar a língua socialmente, quando alguém se torna apto a ler e produzir textos, como notícias, receitas, narrativas, dissertações, reportagens, propagandas, relatos, entre outros, de acordo com as demandas da situação interacional-comunicacional.

Sendo assim, voltando a atenção para os contextos nos quais essa interação ocorre, percebe-se que, atualmente, essa socialização ocorre simultaneamente na web e em espaços físicos, já que os dispositivos móveis permitiram o acesso à internet em qualquer lugar, a qualquer hora (SACCOL et al, 2010).

De fato, a mobilidade se tornou um elemento indispensável para os usuários de tecnologias digitais. $O$ acesso à internet sem a limitação do espaço físico é um dos fatores que levam os sujeitos a passarem mais tempo conectados através de dispositivos móveis. Diversos desenvolvedores de sites e serviços na web, como Facebook, Instagram e Google, destacam também versões para aparelhos móveis, mantendo seus usuários conectados por mais tempo. Conforme Barbosa et al (2015 p. 70), a mobilidade nos processos educativos pode potencializar a aprendizagem autônoma e significativa, pois possibilitam que o indivíduo "leve consigo seu dispositivo, acesse e interaja com os recursos do ciberespaço". 


\section{Observatório}

ISSN n² 2447-4266

Vol. 4, n. 3, maio. 2018

DOI: https://doi.org/10.20873/uft.2447-4266.2018v4n3p540

Juntamente com a preocupação de alfabetizar e letrar, passa-se a analisar também a necessidade de ensinar o jovem a lidar com as características da informação presente na internet e nos dispositivos tecnológicos. Cada vez mais torna-se necessário entender como se relacionam as diferentes formas de letramento com os recursos semióticos disponíveis na web, tendo em vista a multiplicidade de linguagens e de signos que compõem esse espaço. $O$ que leva a multiletramentos e multimodalidades que foca-se a seguir.

\section{b) Multiletramentos e multimodalidades: a informação nas mídias digitais}

Os textos que circulam na web são multimodais, ou seja, são compostos de diversos modos semióticos e linguagens inter-relacionadas na estrutura ou ao redor do corpus do texto. Ao abrir qualquer site, percebe-se que 0 tratamento dado ao material escrito vai além das características linguísticas, pois possuem vídeos, áudios, hiperlinks, imagens, cores, fontes, entre outros, associados ao conteúdo (COSCARELLI \& KERSCH， 2016). Esses textos multimodais fazem uso de diversas linguagens que demandam diferentes tipos de aprendizagem, exigindo que o usuário esteja apto a discernir e compreender linguagem oral, verbal, visual, computacional, entre outras.

Atualmente, não basta apenas ser letrado linguisticamente, faz-se necessário ser letrado também com relação a linguagens não verbais como vídeo, desenho, fotografia, entre outras, afinal, estas são usadas também nos processos de interação social entre os indivíduos de cada cultura, que utilizam a linguagem mais adequada ao processo comunicativo em contexto. $\mathrm{A}$ isso dá-se o nome de multiletramentos, um aspecto do processo educativo que, segundo Coscarelli e Kersch (2016, pg. 7), ao ser trabalhado em sala de aula, promove o desenvolvimento de práticas de letramento abrangentes a toda dimensão da 


\section{Observatório}

ISSN n² 2447-4266

Vol. 4, n. 3, maio. 2018

DOI: https://doi.org/10.20873/uft.2447-4266.2018v4n3p540

cidadania do indivíduo, pois remete "a duas perspectivas: o uso de (novas) tecnologias e a diversidade linguística e cultural, em que o local dialoga com o global".

Para que as práticas pedagógicas trabalhem com letramentos múltiplos e multimodalidades, novamente entra em questão a necessidade de metodologias de ensino e materiais didáticos que sejam adequados ao contexto no qual as tecnologias se inserem. No caso desse estudo, as práticas ocorrem em um espaço não-formal de ensino, o que possibilita a elaboração de atividades específicas para as demandas de aprendizagem que surgem. Uma vez que é comum o uso de jogos digitais nas oficinas promovidas pela pesquisa, optou-se por incorporar o uso de jogos analógicos juntamente com o uso dos recursos nos tablets. Escolheu-se, então, pelo desenvolvimento de partidas de Role Playing Game (jogo de interpretação de papéis), um sistema que se mostrou adequado para o projeto.

\section{Role Playing Game como recurso didático na educação não-formal}

$\mathrm{Na}$ instituição oncológica, contexto deste estudo, diversas famílias recebem apoio social e hospitalar durante o tratamento do familiar com câncer. Além do paciente, irmãos e pais também participam e se envolvem nas atividades oferecidas pela instituição. Assim, no local são realizadas semanalmente oficinas variadas de artes, inglês, artesanato e informática, oportunizando, nesse ambiente, um espaço de educação não-formal criado pela necessidade de oferecer acompanhamento diário às famílias em situação de vulnerabilidade social. Segundo Zucheti e Moura (2010, p.14), ações como essas "são oferecidas às populações para que estas possam aderir de acordo com suas motivações e demandas pessoais". Logo, percebe-se que o processo 


\section{Observatório}

ISSN n² 2447-4266

Vol. 4, n. 3, maio. 2018

DOI: https://doi.org/10.20873/uft.2447-4266.2018v4n3p540

de aprendizagem vai muito além de atividades que acontecem apenas em espaços formais de ensino como escolas, universidades e bibliotecas. Além desses espaços tradicionais, deve-se pensar a educação como uma prática social que pode ser contextualizada em diversos espaços. Aprende-se na escola, sob a orientação de professores; aprende-se em casa, sob orientação de pais ou tutores; e aprende-se em diversos outros espaços, sozinho ou trabalhando em grupo.

No contexto não-formal em foco nesse estudo, a escolha por desenvolver práticas de Role Playing Game ocorreu pelo fato de ser possível inserir qualquer ferramenta tecnológica e qualquer atividade na dinâmica de um jogo de RPG, pois as partidas acontecem de maneira colaborativa, interativa e lúdica, características também presentes em muitos softwares e ferramentas digitais. Além disso, levando em consideração que os sujeitos de nossa pesquisa são crianças e adolescentes, o ato de contar histórias e narrativas faz parte de sua vivência diária, o que contribui para o seu processo de aprendizagem e aquisição de valores da sociedade (SANT'ANNA et al, 2014).

Basicamente, os jogos de Role Playing Game (cuja tradução para o português é "jogo de interpretação de papéis"), surgiram no início dos anos 70 nos Estados Unidos. A proposta era unir a jogabilidade básica de jogos de estratégia com a temática da literatura e desenvolvimento de narrativa. Em um jogo de RPG, cada jogador controla e interpreta uma personagem (criada por ele mesmo) e interage com outros participantes em um universo ficcional criado pelo Dungeon Master, também chamado de "Mestre de Jogo" ou simplesmente "Narrador", que estabelece aos jogadores um desafio a cumprir, que pode ser uma missão para derrotar inimigos, conquistar tesouros, ou qualquer outra coisa que os jogadores quiserem jogar (WINTER, 1999). Dessa 


\section{Observatório}

ISSN n² 2447-4266

Vol. 4, n. 3, maio. 2018

DOI: https://doi.org/10.20873/uft.2447-4266.2018v4n3p540

forma, uma partida de RPG acontece totalmente na imaginação dos participantes e desenvolve-se através da interação e diálogo, já que a construção do jogo ocorre ao mesmo tempo da ação do jogo. Assim, como a linguagem era o instrumento básico para o RPG, o uso de tablets multiplicou a experiência dos alunos com as atividades colaborativas e interativas.

Em si próprio, o RPG é uma prática que abrange múltiplos letramentos e multimodalidades. Diversas linguagens e modos semióticos compõem o jogo, desde o uso de livros, imagens, figuras, dados, cartas, cadernos, leitura, escrita, oralidade, desenho, entre outras. As simulações das histórias envolvem manipular esses diferentes saberes e ferramentas em um contexto no qual quanto maior for a capacidade do jogador de utilizar seus recursos e habilidades, melhor será sua experiência no jogo.

O RPG oferece grandes benefícios para a educação pois desenvolve histórias imaginárias que, tendo ou não relação com o mundo real, demandam uma resposta ativa dos aprendizes. Por exemplo, durante a narrativa, uma decisão precipitada de algum jogador pode colocar em risco a missão, uma decisão bem planejada pode levar à uma grande vitória e decisões individualistas, que não consideram o grupo, podem fazer a equipe inteira fracassar. Assim, no jogo, coloca-se os jogadores na situação de atores em um mundo imaginário, tendo de tomar decisões que, assim como na vida real, terão inevitáveis consequências, sejam elas boas ou não (WINTER, 1999). Como geralmente as histórias são construídas em grupo, qualquer professor, de qualquer disciplina, pode contextualizar as partidas de RPG acordo com o assunto que quiser desenvolver e trabalhar.

Logo, para que fosse explorado ao máximo a interação entre aplicativos e as práticas de alfabetização e letramento, foram criadas diversas atividades 


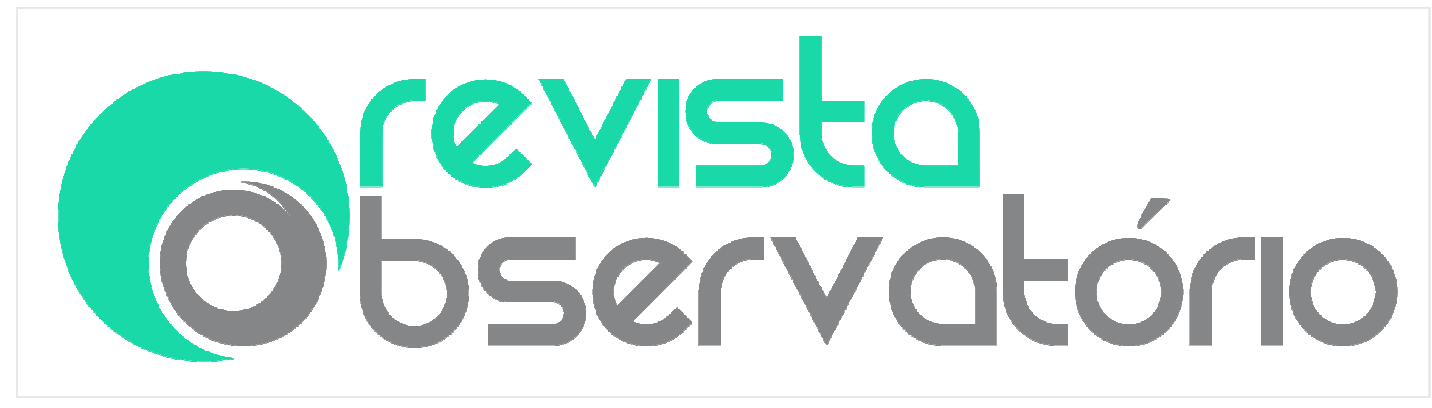

ISSN n² 2447-4266

Vol. 4, n. 3, maio. 2018

DOI: https://doi.org/10.20873/uft.2447-4266.2018v4n3p540

contextualizadas em uma história estruturada, chamada "O Caminho Dos Guerreiros - Uma aventura RPG", com a união de elementos de fantasia medieval, aventura e contos de fadas. Definido o tema, as atividades foram elaboradas de acordo com a metodologia proposta para as oficinas.

\section{Recursos metodológicos}

Definir as metodologias que orientam o trabalho é de fundamental importância para o desenvolvimento das práticas. Desse modo, as oficinas de aprendizagem com mobilidade se caracterizam pela obtenção de dados descritivos sobre a pesquisa e análise qualitativa dos resultados, uma vez que os pesquisadores entram em contato direto com o objeto de estudo (letramento e tecnologia) e com os sujeitos (crianças e adolescentes), de acordo com Godoy (1995). Essa observação é empírica, sendo resultante da percepção do próprio pesquisador quanto aos sujeitos e aos dados coletados.

A realização de oficinas presenciais possibilitou utilizar como método a pesquisa-ação, na qual os pesquisadores, em contato direto com os sujeitos, inserem-se no contexto do problema de pesquisa, participando e agindo para implementar mudanças e avaliar resultados para concluir de maneira satisfatória o estudo (THIOLLENT, 2003).

Os sujeitos da pesquisa foram 3 adolescentes, dois do sexo feminino e um do sexo masculino. Todos frequentam o Ensino Fundamental, entre $\circ 3^{\circ} \mathrm{e} o$ $5^{\circ}$ ano. Um deles está em estágio controlado da leucemia. Cabe ressaltar que na prática pedagógica que antecedeu o trabalho com RPG havia mais um aluno participando das oficinas, o qual teve de se ausentar no segundo semestre devido a um período mais intenso de seu tratamento oncológico. 


\section{Observatório}

ISSN n² 2447-4266

Vol. 4, n. 3, maio. 2018

DOI: https://doi.org/10.20873/uft.2447-4266.2018v4n3p540

A pesquisa foi desenvolvida em um contexto de educação não-formal, pois as oficinas de aprendizagem com mobilidade foram realizadas semanalmente na instituição oncológica. Ao todo, foram 18 oficinas de $2 \mathrm{~h}$ de duração cada, ao longo de 5 meses, no ano de 2016.

O desenvolvimento do projeto ocorreu conforme as seguintes etapas: Primeiro, definiu-se as ações macro (projeto) onde o RPG foi escolhido como prática pedagógica e a estrutura geral concebida. Em seguida, planejou-se as ações micro (encontros e atividades). Passou-se então para a efetiva realização das oficinas, acompanhadas esporadicamente por reuniões para adequações do planejamento e desenvolvimento. Por fim, com base nos dados coletados e observação empírica, fez-se a análise dos resultados.

Os dados foram obtidos pelo pesquisador em contato com os alunos, que registrava o desenvolvimento das oficinas por meio de relatórios semanais, registros fotográficos e coleta de material produzido em aula.

A realização das oficinas foi orientada pelos padrões definidos pela UNESCO (2016). Embora tal documento seja direcionado a docentes, as categorias mostraram-se adequadas para o desenvolvimento das práticas pedagógicas, permitindo avaliar passo a passo o uso das tecnologias. Dessa forma, a UNESCO define três etapas básicas, que foram seguidas, as quais são: (1) alfabetização digital: oficinas livres de apropriação e entretenimento para uso dos dispositivos móveis; (2) aprofundamento do conhecimento: oficinas direcionadas, com uso de aplicativos voltados para o desenvolvimento das atividades propostas (nesse momento, foram desenvolvidas as habilidades de leitura, escrita e raciocínio lógico); (3) criação de conhecimento: nessa fase, os sujeitos compartilharam e discutiram suas produções e atividades. Nesse 


\section{Observatório}

ISSN n² 2447-4266

Vol. 4, n. 3, maio. 2018

DOI: https://doi.org/10.20873/uft.2447-4266.2018v4n3p540

contexto optou-se por analisar os dados da prática de RPG com mobilidade sob três aspectos:

- Avaliação da participação e desenvolvimento dos alunos. analise sobre como os alunos responderam à prática, como participaram, como ocorreu a leitura e escrita.

- Desenvolvimento da competência discursiva: análise do desenvolvimento dos alunos quanto à escrita e letramento linguístico.

- Avaliação das atividades e resultados analise dos resultados das atividades, de modo geral.

\section{Estratégias pedagógicas: atividades de Role Playing Game em oficinas de aprendizagem com mobilidade}

A etapa inicial das oficinas foi a "alfabetização digital". Primeiramente, investigou-se os conhecimentos dos participantes sobre RPG, os quais revelaram desconhecer; na sequência, o mote básico do jogo foi apresentado. Após, cada aluno recebeu um login de conta no google drive (aluno 1, aluno 2, e assim por diante). Os alunos foram instruídos sobre as formas do uso do espaço no drive. Foi solicitado que criassem cinco pastas: "amigos", "tesouros", "equipamentos", "história", "meu personagem" e "monstros". Essas pastas foram destinadas para que os alunos salvassem seus materiais desenvolvidos durante o RPG. Na atividade seguinte, os alunos criaram personagens com uso do aplicativo Autodesk Sketchbook, os quais foram salvos na pasta "meu personagem". Em seguida, fizeram a descrição de seus personagens utilizando o aplicativo Google Docs, também salvando na pasta "meu personagem". Como as oficinas vinham sendo desenvolvidas desde o início do ano em outro projeto 


\section{Observatório}

ISSN n² 2447-4266

Vol. 4, n. 3, maio. 2018

DOI: https://doi.org/10.20873/uft.2447-4266.2018v4n3p540

pedagógico, apenas uma aula foi necessária para aprenderem a utilizar as ferramentas, pois já estavam habituados ao uso dos tablets.

$\mathrm{Na}$ semana seguinte, iniciou-se a etapa de "aprofundamento de conhecimento", onde foi narrado o início da história aos alunos, pois a narrativa faria parte de diversos encontros. Em cada aula, os alunos foram instruídos a salvarem seus registros de participação no RPG na forma de um diário de bordo, ou "diário de viagem". A cada semana, foi desenvolvida uma atividade específica, conforme relatado no item dos resultados das práticas desenvolvidas. Em todas as atividades foi seguida uma ordem básica: os alunos aprendiam a mexer na ferramenta nova, testavam-na, e, então, produziam a atividade. Nessa sequência, o RPG perdurou por 14 oficinas.

Nas últimas três oficinas, durante a etapa "criação de conhecimento", os alunos fizeram postagens em blogs criados para suas contas no Gmail. Cada aluno fez em seu blog postagens sobre: um jogo de tablet de sua preferência; um desenho/série que costumam assistir e o seu relato da história RPG. Alguns participantes compartilharam entre os colegas a sua história. Na última oficina foi entregue impresso a cada aluno as atividades que desenvolveram nas oficinas durante o semestre.

a) Aspectos referentes à construção da história "O Caminho dos Guerreiros Uma aventura RPG"

Para que um jogo de RPG aconteça é necessária uma história que sirva de base para os jogadores tomarem suas decisões e cumprirem suas missões. Dessa forma, não basta pensar na lógica da jogabilidade - uma pessoa narrando e fazendo perguntas e outras tomando decisões - mas é preciso, 


\section{Observatório}

antes de tudo, um cenário no qual as decisões das personagens estejam contextualizadas e façam sentido.

Assim, decidiu-se por criar uma história de acordo com o perfil e gostos dos sujeitos da pesquisa. Criou-se, então, a narrativa "O caminho dos guerreiros - Uma aventura RPG", cuja sinopse básica pode ser descrita da seguinte forma: Um cientista louco chamado Dr. Stein sequestra a princesa de um reino conhecido como Reino Dourado, levando-a para uma montanha muito distante chamada Logali. Para resgatá-la, um grupo de guerreiros deve atravessar todo o continente em busca das quatro joias místicas do poder e leva-las à montanha Logali, pois essa é a única maneira de libertar a princesa e derrotar o cientista malvado.

$\mathrm{Na}$ história, foram unidos elementos variados de diversos gêneros e temáticas, como fantasia, ficção científica, aventura, entre outras. Dentre os arquétipos e estereótipos, têm-se a figura de uma princesa e um rei, comum aos contos de fadas; a presença de goblins e criaturas mitológicas, comuns a histórias de fantasia medieval; têm-se a referência à ficção científica, com cidades e países futurísticos, entre outros. Essa miscelânea provou ser uma escolha certa, já que abrangeu os gostos e interesses dos três sujeitos que fizeram parte da pesquisa.

Um dos elementos importantes para o desenvolvimento dessa história foi a criação das personagens dos alunos. Cada participante criou sua personagem, estabelecendo nome, idade e características físicas. Toda vez que agissem na história, deveriam assumir a postura de seu avatar e interagir conforme suas habilidades e valores pessoais. Isso produziu uma conexão entre os alunos e a história, pois o mundo fictício tornou-se também o lugar de interação nas oficinas. 


\section{Observotório}

ISSN n² 2447-4266

Vol. 4, n. 3, maio. 2018

DOI: https://doi.org/10.20873/uft.2447-4266.2018v4n3p540

A progressão da história foi sendo construída ao longo das semanas e de acordo com as ideias de atividades. Por exemplo, para se trabalhar com desenho, narrou-se que as personagens encontravam um gnomo que não gostava de receber visitas e que continha uma informação preciosa sobre o caminho até a montanha onde a princesa estava. Em troca da informação, ele pedia que os guerreiros criassem placas para afastar intrusos de sua residência. Assim, os alunos tiveram de baixar o aplicativo Autodesk Sketchbook, ferramenta apropriada para a tarefa, e desenhar a placa para o gnomo. Em outra atividade, os alunos chegavam em uma cidade na qual um homem distribuía códigos QR ("quick response" - códigos de resposta rápida) que davam acesso a ingressos grátis de cinema, em comemoração ao dia das crianças. Esses códigos abriam uma página na web contendo o pôster de cada filme, como Rei Leão, Minions, Madagascar, entre outros, sendo uma atividade bem divertida para os alunos pois não sabiam qual filme iriam conseguir.

Logo, ao construir a história de acordo com as tarefas a serem desenvolvidas, foram definidas atividades que abrangessem diversos tipos de letramento e modalidades semióticas, sempre utilizando os tablets para realização.

\section{b) Objetivos didáticos propostos através do jogo de RPG}

Para que os alunos aprendessem a lidar com diferentes formas de letramento, não apenas o linguístico, optou-se por atividades que explorassem diferentes recursos semióticos em sua composição. Foram selecionados, então, aplicativos apropriados, que foram baixados e instalados nos tablets.

Os desenhos foram realizados com uso do aplicativo Autodesk Sketchbook. Esse é um tipo de letramento importante, pois o aluno, além de 


\section{Observatório}

ISSN n² 2447-4266

Vol. 4, n. 3, maio. 2018

DOI: https://doi.org/10.20873/uft.2447-4266.2018v4n3p540

desenvolver sua criatividade, aprende a explorar cores, formas, objetos e traçados específicos na construção do desenho.

A atividade de escrita foi desenvolvida com uso do aplicativo google docs e ocorreu como parte dos objetivos principais do projeto de oficinas de aprendizagem com mobilidade, que é auxiliar no desenvolvimento da competência linguística e discursiva dos alunos, uma vez que a língua é um instrumento de interação na sociedade conforme ressalta Soares (1998).

Em determinado momento das oficinas, optou-se por produzir a escrita utilizando outra ferramenta além do Google Docs, com a escolha do aplicativo Comic Stript It, para produção de histórias em quadrinhos. Esse é um tipo de atividade na qual o uso de recursos multimodais e múltiplas linguagens é essencial para sua realização. Foi solicitado aos alunos que prestassem atenção quanto a cores, imagens, fontes textuais, tamanho dos balões de fala e disposição dos quadrinhos. Ao terem de organizar tanta informação distinta na história em quadrinhos, cada aprendiz pôde desenvolver sua percepção da diferença que cada tipo de linguagem provoca na construção do texto. Segundo Cani \& Coscarelli (2016, p.18), trabalhar com textos multimodais, neste caso as histórias em quadrinhos, "cria oportunidades para os professores mostrarem aos alunos que há um propósito comunicativo na associação de linguagem verbal à não verbal".

A utilização dos espaços virtuais deu-se pela necessidade de também promover o letramento digital dos alunos. Com o aplicativo Google Drive, os alunos foram ensinados acerca dos caminhos existentes no espaço da web para compartilhar e salvar a informação que produziam. Esse também é um saber importante, pois, embora utilizem diariamente as tecnologias, muitos usuários não conhecem por completo os recursos, conforme coloca Matias (2016, p. 177), 


\section{Observatório}

ISSN n² 2447-4266

Vol. 4, n. 3, maio. 2018

DOI: https://doi.org/10.20873/uft.2447-4266.2018v4n3p540

ao afirmar que "(os alunos) realizam automaticamente ações que os levam sempre aos mesmos lugares, aos mesmos sites, aos mesmos jogos".

Para desenvolver o raciocínio lógico, foi trabalhado em uma oficina com enigmas e charadas matemáticas ocultas em códigos $Q R$, que foram espalhados pelas salas da instituição. Foi utilizado um leitor específico para esses códigos, tornando-se possível ensinar aos alunos um mecanismo mais fácil de acesso à links e arquivos. Além disso, cabe ressaltar que a própria prática do RPG desenvolve esse tipo de habilidade, como abordado no referencial teórico por Winter (1999), afinal, ter de tomar decisões para que suas personagens evoluam na história demanda de cada aluno pensar de maneira lógica e reflexiva.

O uso do jogo Crafting Game deu-se com o objetivo de aproveitar os recursos de construção de mundo disponíveis na plataforma, explorando as potencialidades pedagógicas do jogo, no qual é possível criar um mundo virtual e interagir com outros usuários. Essa ferramenta pode contribuir muito para atividades que envolvem narrativas, sejam elas visuais ou textuais, demonstrando que é possível aprender através de jogos de entretenimento, conforme coloca Prensky (2012).

Outras atividades foram elaboradas com vistas para exploração de recursos diversificados, instalados nos dispositivos móveis que julgou-se interessantes para as oficinas, dentre os quais se destacam Google Handwriting, para inserção de texto manual, e Voice Changer, editor de áudio. Essas ferramentas foram utilizadas com objetivo de tornar algumas oficinas mais lúdicas e variadas.

Já a produção de um blog para cada aluno, foi pensada com base na etapa de criação de conhecimento das definições da UNESCO (2016). Ao compartilhar na web suas atividades, os alunos se tornam participantes do 


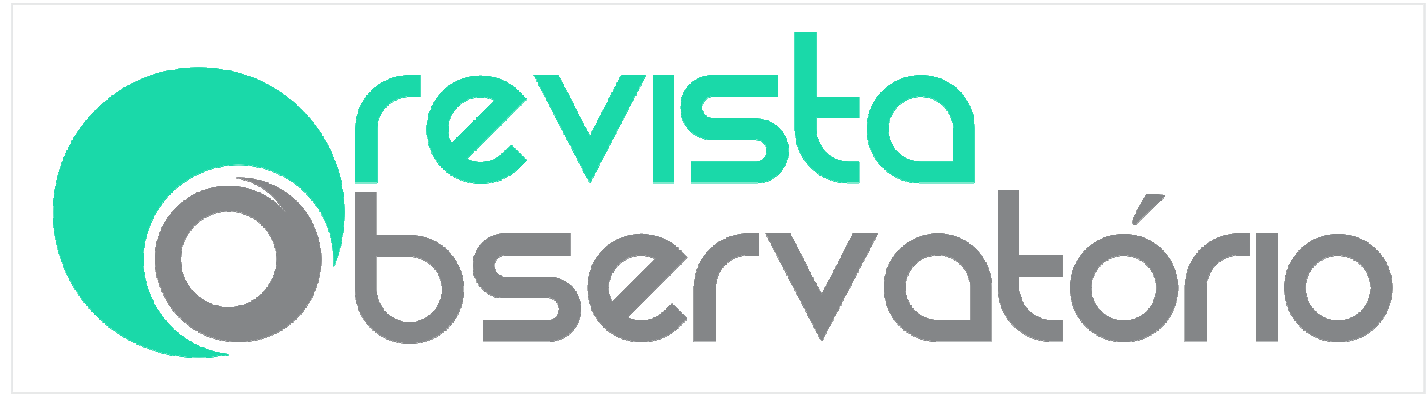

ISSN n² 2447-4266

Vol. 4, n. 3, maio. 2018

DOI: https://doi.org/10.20873/uft.2447-4266.2018v4n3p540

processo de difusão e produção de conhecimento que as tecnologias móveis permitiram aos usuários.

Como referido no tópico anterior, todas essas atividades foram inseridas na história do RPG. Portanto, toda a prática de ensino foi contextualizada no mundo imaginário da narrativa do jogo, demandando dos alunos um uso objetivo da linguagem.

\section{Resultados das práticas desenvolvidas}

Para análise dos dados, utilizou-se as categorias definidas na metodologia. O corpus de análise foi coletado no decorrer das oficinas de RPG.

\section{a) Avaliação dos resultados atingidos nas atividades do RPG}

As atividades desenvolvidas durante o RPG são apresentadas no quadro um. As análises são fundamentadas nas concepções de multiletramentos e multimodalidades, discutidas em Kersch \& Rabello (2016) e nos estudos acerca dos benefícios do uso de tecnologias móveis na educação (PRENSKY, 2001, 2012) (BARBOSA et al, 2015).

Quadro 1: Relação de atividades e resultados

\begin{tabular}{|l|l|}
\hline Atividade & Resultado \\
\hline $\begin{array}{l}\text { 1. Escrita, utilizando Google Docs. } \\
\text { Durante as oficinas, os alunos foram } \\
\text { orientados a registrar um diário de } \\
\text { viagem, escrevendo o relato da aventura } \\
\text { RPG de cada dia. }\end{array}$ & $\begin{array}{l}\text { Escrever nos tablets se tornou uma atividade } \\
\text { diferenciada para os alunos, pois possibilitou } \\
\text { utilizar cores, fontes, tamanhos e posições variadas } \\
\text { e também inserir emoticons no texto. Além disso, } \\
\text { escrever uma história na qual eles mesmos eram } \\
\text { participantes ativos fez com que escrevessem com } \\
\text { bastante entusiasmo, tornando-se protagonistas do } \\
\text { seu desenvolvimento. }\end{array}$ \\
\hline $\begin{array}{l}\text { 2. Criação de espaço virtual no Google } \\
\text { Drive. Os alunos criaram diversas pastas }\end{array}$ & $\begin{array}{l}\text { Os alunos aprenderam a criar espaços virtuais para } \\
\text { organização de conteúdos e arquivos pessoais. }\end{array}$ \\
\hline
\end{tabular}




\section{Observatório}

ISSN n² 2447-4266

Vol. 4, n. 3, maio. 2018

DOI: https://doi.org/10.20873/uft.2447-4266.2018v4n3p540

\begin{tabular}{|c|c|}
\hline Atividade & Resultado \\
\hline \multicolumn{2}{|l|}{$\begin{array}{l}\text { no aplicativo/site Google Drive, para que } \\
\text { guardassem nelas as produções durante } \\
\text { o jogo. }\end{array}$} \\
\hline $\begin{array}{l}\text { 3. Compartilhamento de arquivos via } \\
\text { Google Drive. O pesquisador } \\
\text { compartilhava com os alunos as } \\
\text { recompensas adquiridas ao longo do } \\
\text { RPG, inserindo diretamente nas pastas } \\
\text { dos alunos. }\end{array}$ & $\begin{array}{l}\text { Os alunos aprenderam que é possível compartilhar } \\
\text { informação em tempo real na internet, fazendo a } \\
\text { troca de arquivos de maneira rápida e prática. }\end{array}$ \\
\hline $\begin{array}{l}\text { 4. Desenhos, utilizando o aplicativo } \\
\text { Autodesk Sketchbook. Essa atividade foi } \\
\text { contextualizada em dois momentos: No } \\
\text { primeiro, eles desenharam as suas } \\
\text { personagens. No segundo, eles tiveram } \\
\text { que desenhar uma placa do tipo "não } \\
\text { entre", já que, no contexto da história, } \\
\text { uma criatura exigia essa tarefa como } \\
\text { troca para conceder-lhes uma importante } \\
\text { informação. }\end{array}$ & $\begin{array}{l}\text { Essas duas ocasiões demonstraram como } \\
\text { diferentes tarefas, nesse caso o desenho e a escrita, } \\
\text { podem, em um contexto maior, auxiliarem na } \\
\text { construção de sentido acerca de algo, pois os } \\
\text { alunos tinham que cuidar para não contradizer o } \\
\text { que havia sido escrito sobre as características das } \\
\text { personagens. No desenho da placa, um dos alunos } \\
\text { escreveu "stop", associando também a língua } \\
\text { inglesa como fator de produção de sentido em seu } \\
\text { desenho. }\end{array}$ \\
\hline $\begin{array}{l}\text { 5. Fotografia: Os alunos fotografaram } \\
\text { diversos espaços da instituição para } \\
\text { conquistar um objetivo no contexto da } \\
\text { história do RPG. }\end{array}$ & $\begin{array}{l}\text { Os alunos assumiram um posicionamento crítico ao } \\
\text { fazerem as fotografias, explorando ângulos, } \\
\text { direções, posições, efeitos. Além disso, fazer a } \\
\text { atividade ao ar livre também fez com que eles } \\
\text { aproveitassem a mobilidade dos dispositivos e } \\
\text { interagissem com a natureza e outros espaços. }\end{array}$ \\
\hline $\begin{array}{l}\text { 6. Brincadeiras com textos trava-língua, } \\
\text { utilizando o aplicativo Voice Changer. } \\
\text { Esse aplicativo altera o som de gravações } \\
\text { de voz, produzindo efeitos variados. }\end{array}$ & $\begin{array}{l}\text { Essa atividade envolveu o trabalho com oralidade } \\
\text { relacionada à tecnologia, neste caso, recursos de } \\
\text { edição de som. Os alunos testaram frases com } \\
\text { diferentes efeitos, como voz aguda, voz grave, voz } \\
\text { de marciano, voz de robô, entre outros efeitos. Essa } \\
\text { atividade fez todos os alunos, mesmos os mais } \\
\text { tímidos, se expressarem e interagirem entre si. }\end{array}$ \\
\hline $\begin{array}{l}\text { 7. História em quadrinhos, com uso do } \\
\text { aplicativo Comic Stript IT: Foi solicitado a } \\
\text { escrita do relato de uma das oficinas em } \\
\text { formato de história em quadrinhos, } \\
\text { escolhendo imagens relacionadas com a } \\
\text { história e escrevendo balões de fala e } \\
\text { legendas. }\end{array}$ & $\begin{array}{l}\text { Essa atividade envolveu pesquisa na internet, } \\
\text { seleção de imagens, escrita, edição de imagem e } \\
\text { de escrita. Cada aluno produziu uma curta história } \\
\text { em quadrinhos. O cuidado com os balões de fala } \\
\text { (tamanho, posição), escrita (ortografia, cores, fonte, } \\
\text { tamanho) e com as imagens (escolhidas de acordo } \\
\text { com a história) fizeram os alunos refletirem acerca }\end{array}$ \\
\hline
\end{tabular}




\section{Observatório}

ISSN n² 2447-4266

Vol. 4, n. 3, maio. 2018

DOI: https://doi.org/10.20873/uft.2447-4266.2018v4n3p540

\begin{tabular}{|c|c|}
\hline Atividade & Resultado \\
\hline & do aspecto visual que a produção final deveria ter. \\
\hline $\begin{array}{l}\text { 8. Escrita manual nos tablets, com uso do } \\
\text { aplicativo Google Handwriting. Mudando } \\
\text { novamente o formato de inserção de } \\
\text { textos nos dispositivos, os alunos } \\
\text { escreviam manualmente no teclado do } \\
\text { Google Handwriting e o aplicativo } \\
\text { digitalizava os caracteres em uma fonte } \\
\text { comum. }\end{array}$ & $\begin{array}{l}\text { Esse aplicativo faz a inserção de texto de maneira } \\
\text { diferenciada. Os alunos testaram qual estilo de } \\
\text { letra ficava melhor, pois precisam escrever de um } \\
\text { jeito que o aplicativo pudesse analisar os caracteres } \\
\text { e digitaliza-los. Alguns tentaram a escrita cursiva e } \\
\text { o aplicativo detectou corretamente as letras e } \\
\text { palavras, outros só conseguiram utilizando caixa } \\
\text { baixa ou caixa alta. Assim, eles perceberam que o } \\
\text { mínimo necessário era que sua letra fosse legível, já } \\
\text { que o estilo do traçado não afetava a digitalização. }\end{array}$ \\
\hline $\begin{array}{l}\text { 9. Charadas e contas matemáticas com } \\
\text { leitor de } Q R \text { Code. Os códigos impressos } \\
\text { de arquivo } Q R \text { Codes foram espalhados } \\
\text { por diversos locais da AMO. Os códigos } \\
\text { davam acesso a imagens com charadas e } \\
\text { contas matemáticas simples. No contexto } \\
\text { da história, se acertassem os enigmas, } \\
\text { ganhariam uma recompensa. }\end{array}$ & $\begin{array}{l}\text { Aqui, uniu-se raciocínio lógico, matemática, leitura } \\
\text { e pesquisa na internet, além de explorar a } \\
\text { mobilidade dos dispositivos. Mais um exemplo de } \\
\text { que diferentes letramentos (linguagem verbal, } \\
\text { leitura, matemática) e recursos tecnológicos ( } q r \\
\text { codes e tablets) podem estar unidos em práticas } \\
\text { interativas e criativas, já que os alunos ficavam na } \\
\text { expectativa de procurar os qr codes, descobrir qual } \\
\text { seria a questão e resolvê-la. }\end{array}$ \\
\hline $\begin{array}{l}\text { 10. Criação de um mundo virtual, com } \\
\text { uso do jogo Crafting Game. Em } \\
\text { determinado momento da história do } \\
\text { RPG, as personagens adentravam uma } \\
\text { cidade subterrânea que havia sido } \\
\text { destruída por um terremoto. Para ajudar } \\
\text { os moradores, cada jogador teve que } \\
\text { reconstruir a cidade utilizando esse } \\
\text { aplicativo, que se assemelha ao jogo } \\
\text { Minecraft, possuindo funções e recursos } \\
\text { básicos. }\end{array}$ & $\begin{array}{l}\text { Com uso do jogo, os alunos demonstraram como } \\
\text { imaginavam ser o mundo narrado a eles. Essa } \\
\text { representação visual representou bem a percepção } \\
\text { dos alunos quanto ao sentido da história, pois } \\
\text { todos criaram uma cidade virtual adequada à tarefa } \\
\text { exigida. }\end{array}$ \\
\hline $\begin{array}{l}\text { 11. Postagem em blogs. Após o término } \\
\text { da atividade de RPG, os alunos postaram } \\
\text { os relatos em blogs criados para cada um. }\end{array}$ & $\begin{array}{l}\text { Os alunos aprenderam a fazer postagens em blogs } \\
\text { e a construir o seu espaço virtual }\end{array}$ \\
\hline
\end{tabular}

Fonte: Os autores

$\mathrm{Na}$ sequencia apresenta-se uma análise resultados que demonstra a contribuição para o letramento, alfabetização e nos déficits de aprendizagem 


\section{Observatório}

ISSN n² 2447-4266

Vol. 4, n. 3, maio. 2018

DOI: https://doi.org/10.20873/uft.2447-4266.2018v4n3p540

de crianças e adolescentes em tratamento oncológico em um contexto nãoformal de ensino a que este estudo se propôs.

\section{b) Desenvolvimento da competência discursiva}

No que tange ao desenvolvimento linguístico, o enfoque da prática de RPG foi trabalhar com tarefas nas quais a escrita e a leitura faziam parte de um contexto maior, corroborando, assim, com as noções de letramento discutidas em Travaglia (2015).

A escrita foi um elemento importante para o desenvolvimento do RPG pois através dela a história mantinha sua progressão correta, funcionando como um mapa para os alunos de toda a trajetória do RPG. A proposta dessa atividade era, principalmente, fazer com que os alunos associassem a escrita a uma prática continua contextualizada na rotina das oficinas. Nesse aspecto, os sujeitos souberam utilizar a língua escrita interagindo através do texto, conforme a teoria sócio-interacionista discutida por Koch \& Elias (2009).

Quanto à ortografia, os alunos tiveram bons progressos. Percebeu-se que a principal dificuldade que tinham era de fazer a correspondência correta entre grafemas e fonemas. Por exemplo, um dos alunos frequentemente fazia correspondência do fonema "ch" com o grafema "s", como em "segou" (chegou). Para observar a origem desse equívoco, fez-se um teste com o aluno para saber se em sua pronúncia do fonema "ch" estava soando como "s". Mostramos diversas imagens de objetos variados (contextualizando isso na história do RPG) e percebeu-se que havia na fala do aluno a sonoridade do "ch" parecida com "s", o que justificaria sua falha. 


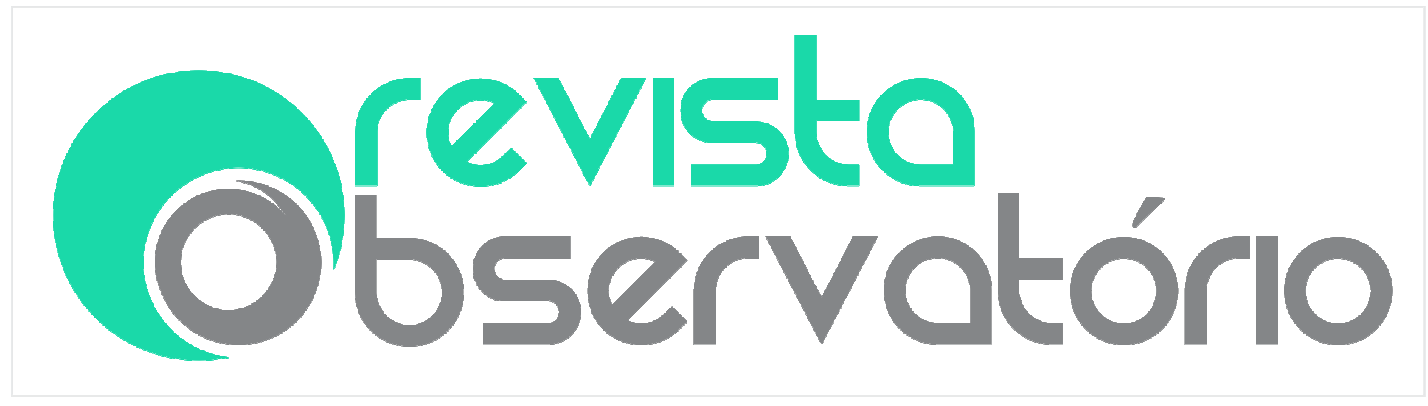

ISSN n² 2447-4266

Vol. 4, n. 3, maio. 2018

DOI: https://doi.org/10.20873/uft.2447-4266.2018v4n3p540

Essa dificuldade dos alunos foi corrigida graças à dinâmica do Role Playing Game. A narração da história foi um dos fatores determinantes para esse resultado, pois, ao verbalizarem para o professor suas ações na história, os alunos digitavam partindo da própria manifestação oral do texto. Assim, o professor auxiliava os alunos pedindo que escrevessem suas ações e em seguida falassem ao grupo, fazendo com que relessem seu texto e se dessem conta do que escreveram. Nesse momento, os próprios alunos corrigiam seu texto ou pediam ajuda do professor, desenvolvendo sua consciência linguística. De acordo com as autoras Wolff e Nazari (2009, p. 155), esse é um dos benefícios que essas interações e momentos produzem, pois, "um investimento válido e bem estruturado da oralidade só poderá trazer repercussões positivas para o objeto-linguagem na sua forma escrita". Para concluir, foram dedicadas algumas oficinas para correção dos textos completos, com o pesquisador dando atenção individual a cada aluno.

c) Avaliação da participação e desenvolvimento dos alunos:

Os sujeitos responderam de forma positiva ao RPG e participaram ativamente da história. A interação era sempre proveitosa e a ludicidade do jogo foi uma constante. A seguir, são descritos alguns exemplos das perguntas feitas pelo professor durante a história, e exemplos de escrita, retirada de cada texto dos alunos ${ }^{5}$ :

\footnotetext{
${ }^{5}$ Possui aprovação do comitê de ética da instituição e a identidade dos sujeitos foi preservada.
} 


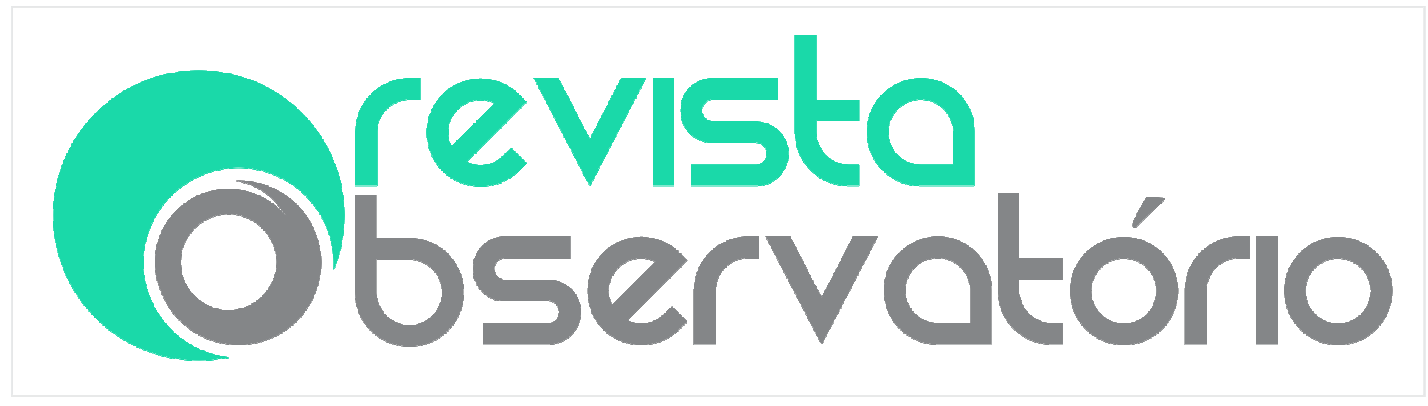

ISSN n² 2447-4266

Vol. 4, n. 3, maio. 2018

DOI: https://doi.org/10.20873/uft.2447-4266.2018v4n3p540

Situação 1:

Pesquisador: (...) O prefeito diz para vocês seguirem até as ruínas da antiga cidade, que fica nas montanhas a leste. Vocês vão em direção até lá. No caminho, vocês encontram um homem idoso caído no chão e a carroça dele quebrada. O que cada um de vocês vai fazer?

Aluno 1: Eu ajudo a consertar a carroça.

Aluno 2: Eu ajudo a cuidar dos machucados do homem.

Aluno 3. FII cıido dos ferimentos do homem. Fll nerounto se ele sahe dos

Em relação ao texto propriamente dito, os alunos fizeram relatos básicos, escritos em forma de tópicos elencados de forma contínua. Ficaram registradas apenas as ações principais, sendo todos esses tópicos contextualizados dentro de uma história muito maior, concluída ao final do período das oficinas.

Devido à prática de RPG ter se estendido até o final das oficinas, não foi

Aluno 1: Dia 1. Saímos de manhã. Chegamos na ponte. Cantei a música "atirei o pau no gato". Subi com uma corda na árvore. Eu ia conversar com o homem.

possível fazer a reescrita e aprofundamento da história que cada aluno vivenciou com sua personagem, o que teria sido bom para aprimorar o material escrito e também ensiná-los sobre alguns aspectos da construção de um texto narrativo.

A seguir apresenta-se um quadro com uma representação visual das oficinas. 


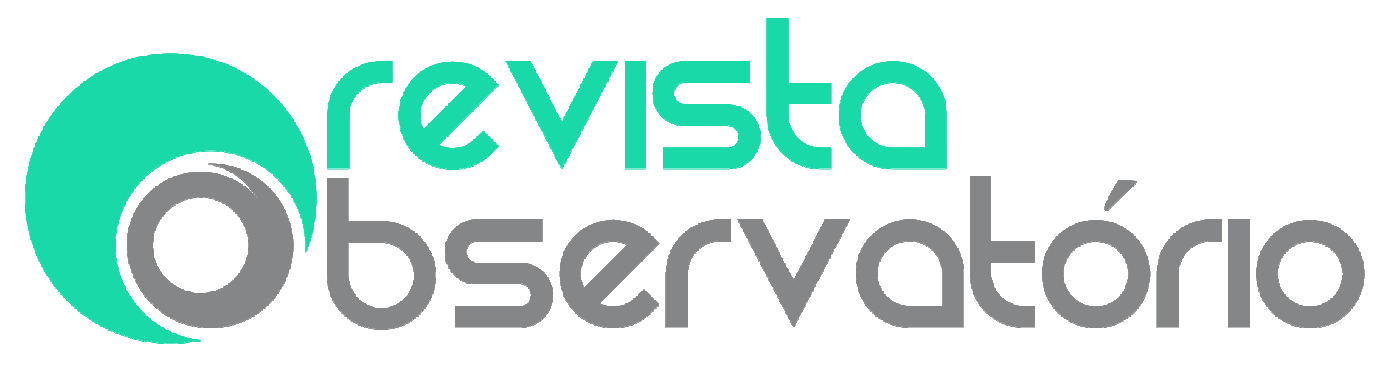

ISSN n² 2447-4266

Vol. 4, n. 3, maio. 2018

DOI: https://doi.org/10.20873/uft.2447-4266.2018v4n3p540

Quadro 1: Relação de atividades e resultados

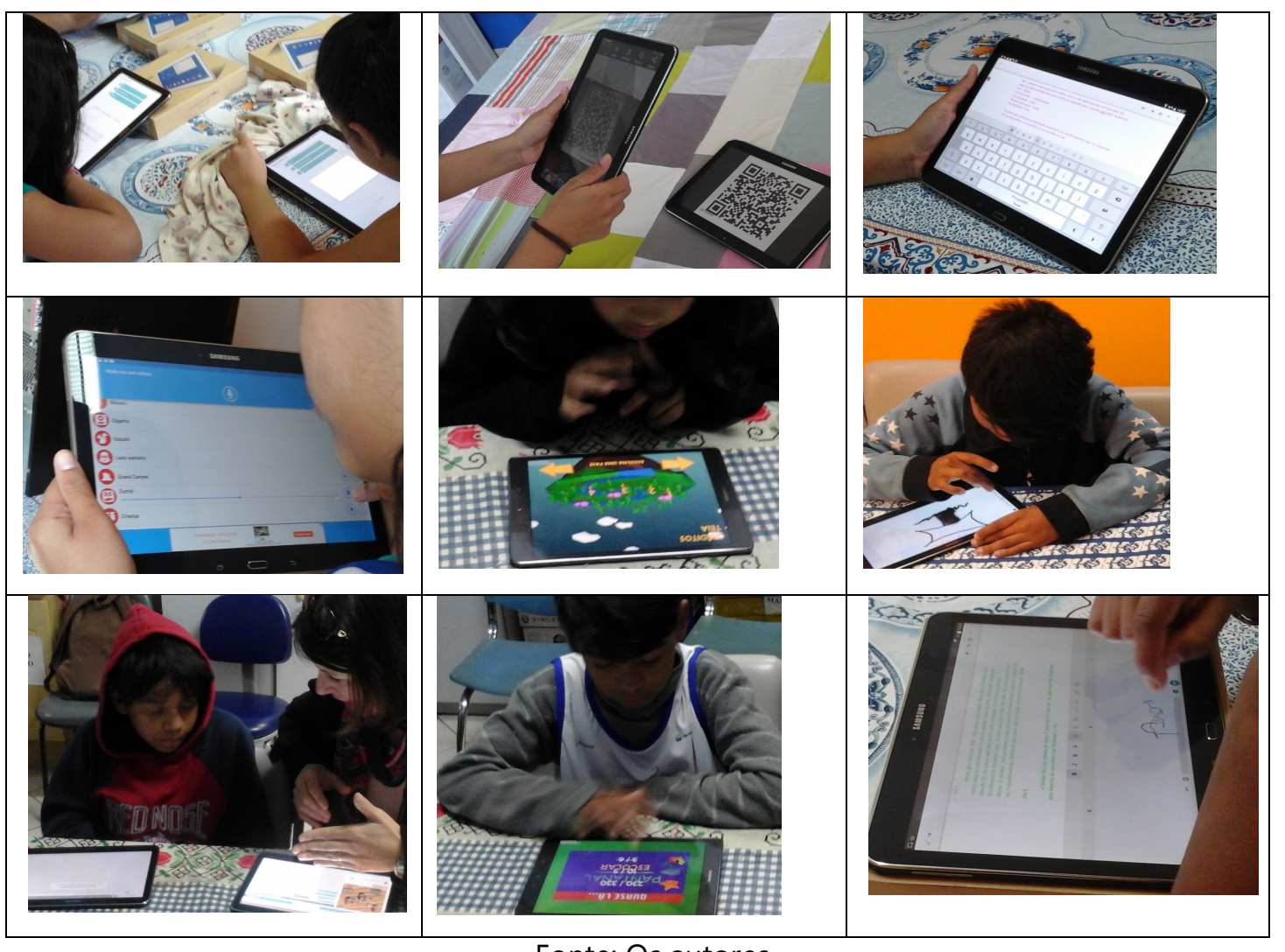

Fonte: Os autores

Como forma de fechamento da análise dos resultados, considerou-se importante retomar-se os padrões da UNESCO (2016) nas três etapas básicas. No que se refere à alfabetização digital, pode-se dizer que essa etapa foi contemplada com êxito nas oficinas, uma vez que os alunos utilizaram os dispositivos tablets em todas atividades e com emprego de diversos aplicativos e acesso à web. O uso de tais recursos, no decorrer das oficinais, proporcionou aos alunos conhecimento, desenvoltura e dinamismo no uso dos dispositivos e aplicativos. A segunda etapa, que trata do aprofundamento do conhecimento, 


\section{Observatório}

ISSN n² 2447-4266

Vol. 4, n. 3, maio. 2018

DOI: https://doi.org/10.20873/uft.2447-4266.2018v4n3p540

também considera-se plenamente atingida, o que pode ser constatado pela produção textual e leitura no decorrer das atividades realizadas, conforme quadro 1. Por fim, a terceira etapa, que trata da criação de conhecimento, foi contemplada principalmente pelas atividades três e onze.

\section{Considerações finais}

De acordo com os dados obtidos nesta pesquisa, pôde-se verificar que a realização de práticas com dispositivos móveis tablets e jogos de Role Playing Game (RPG) motivou o desenvolvimento da leitura, escrita e raciocínio lógico dos alunos envolvidos. O uso de recursos tecnológicos e web, no decorrer das oficinas, proporcionou aos alunos conhecimento, desenvoltura e dinamismo no uso da internet, dispositivos e aplicativos, ampliando consideravelmente sua alfabetização digital.

O desenvolvimento dos aspectos de leitura, escrita e raciocínio lógico durante as atividades com o uso desses dispositivos ocorreu de forma lúdica, dinâmica e interativa e levou os alunos a adquirirem habilidades cognitivas para além do seu percebimento, tornando-os protagonistas de seu próprio desenvolvimento. Percebeu-se também que as atividades contribuíram para o processo de letramento dos alunos, não apenas no linguístico, mas também abrangendo múltiplos letramentos e modos semióticos, potencializados pelo caráter das práticas.

Neste trabalho, foi apresentado apenas uma forma de desenvolvimento em contexto não-formal de ensino, com uso de mobilidade, aplicativos e internet em prol da ampliação da leitura, escrita e raciocínio lógico. Como sugestão para um trabalho futuro, essas práticas podem ser utilizadas em contexto de uma turma do ensino básico, em projeto de caráter interdisciplinar. 


\section{Observatório}

ISSN n² 2447-4266

Vol. 4, n. 3, maio. 2018

DOI: https://doi.org/10.20873/uft.2447-4266.2018v4n3p540

Quanto às pesquisas em contexto não formal realizadas na instituição oncológica, um novo projeto está em execução com o tema água e sustentabilidade.

\section{Referências}

BARBOSA, D. N. F.; BASSANI, P. B. S.; MARTINS, R. L.; MACIEL, B. L. Experiências com o uso de tablets no contexto da educação escolar e não escolar. IN: Revista PRÂKSIS, Feevale, Novo Hamburgo, a. 12, v. 2, p. 67-80. 2015.

CANI, J. B.; COSCARELLI, C. V. Textos multimodais como objetos de ensino: reflexões em propostas didáticas" IN: KERSCH, D. F.; COSCARELLI, C. V.; CANI, J. B. (Orgs.) Multiletramentos e Multimodalidade: ações pedagógicas aplicadas à linguagem. Campinas: Editora Pontes. 2016.

COSCARELLI, C. V.; KERSCH, D. F. Pedagogia dos multiletramentos: Alunos conectados? Novas escolas + novos professores. IN: KERSCH, D. F.; COSCARELLI, C. V.; CANI, J. B. (Orgs.) Multiletramentos e Multimodalidade: ações pedagógicas aplicadas à linguagem. Campinas: Editora Pontes. 2016

GODOY, A. S. Introdução à pesquisa qualitativa. IN: Revista de administração de empresas, São Paulo, v.35, n.2, p.57-63. 1995

KERSCH, D. F.; RABELLO, K. R. São atitudes como estas que podem fazer a diferença para uma escola melhor: outros tempos, novos letramentos. IN: KERSCH, D. F.; COSCARELLI, C. V.; CANI, J. B. (Orgs.) Multiletramentos e Multimodalidade: ações pedagógicas aplicadas à linguagem. Campinas: Editora Pontes. 2016

KOCH, I. V.; ELIAS, V. M. Ler e Escrever - estratégias de produção textual. São Paulo: Contexto. 2009

MATIAS, J. O Google Drive como ferramenta de escrita colaborativa do gênero projeto de pesquisa: um caminho para o letramento digital. IN: KERSCH, D. F.; COSCARELLI, C. V.; CANI, J. B. (Orgs.) Multiletramentos e Multimodalidade: ações pedagógicas aplicadas à linguagem. Campinas: Editora Pontes. 2016

PRENSKY, M. Trivia Vs Power - Let's be clear on exactly how we are using technology in education. In. Educational Technology. 2012. Disponível em: 


\section{Observatório}

ISSN n² 2447-4266

Vol. 4, n. 3, maio. 2018

DOI: https://doi.org/10.20873/uft.2447-4266.2018v4n3p540

$<$ http://marcprensky.com/writing/Prensky-Trivia_vs_Power-EdTech-JulyAug2012.pdf> Acesso em: 24 fev. 2017

PRENSKY, M. Digital Natives Digital Immigrants. In: PRENSKY, Marc. On the Horizon. NCB University Press, vol. 9, n. 5, 2001. Disponível em http://www.marcprensky.com/writing/. Acesso em: 15 de jun., 2017.

SACCOL, A I. C. Z.; SCHELEMER, E; BARBOSA, J. L. V. M-learning e u-learning: Novas Perspectivas da Aprendizagem Móvel e Ubíqua. 1. ed. São Paulo: Pearson Prentice Hall, 2010

SANTA'ANNA, V. L. et al. A importância da contação de história como prática educativa na educação infantil. IN: Pedagogia em ação. PUC-Minas. Belo Horizonte. 2014 Disponível em: <http://periodicos.pucminas.br/index.php/pedagogiacao/article/viewFile/8477/ 7227> Acesso em: 24 fev. 2017

SOARES, M. Letramento: tema em três gêneros. Belo Horizonte: Autêntica. 1998

THIOLLENT, M. Metodologia da pesquisa-ação. 12.ed. São Paulo: Cortez. 2003

TRAVAGLIA, L. C. Letramento e conhecimento linguístico. IN: Letras \& Letras. Uberlândia: Instituto de Letras e Linguística / Universidade Federal de Uberlândia, v.31, n.3, p. 158-172. Minas Gerais, 2015.

UNESCO (org). 2009 Padrões de Competência em TIC para Professores. Disponível em: http://unesdoc.unesco.org/images/0015/001562/156209por.pdf. Acesso em: 20 ago. 2017.

WINTER, S. Dungeons \& Dragons Avançado: Livro do jogador. São Paulo; Devir, 1999

WOLFF, C. L.; NAZARI, G. T. A Importância da Oralidade no Processo de Alfabetização. IN: Letrônica. v. 2, n. 1. PUC-RS. 2009. Disponível em: < http://revistaseletronicas.pucrs.br/ojs/index.php/letronica/article/view/4966/406 5> Acesso em: 19 ago. 2017

ZUCHETI, D. T.; MOURA, E. O. G. Práticas Educativas e formação de Educadores: novos desafios no campo social. IN: Ensaio - Aval. Pol. Publ. Educ. Rio de Janeiro, v. 18, n. 66, p. 9- 28, 2010. 